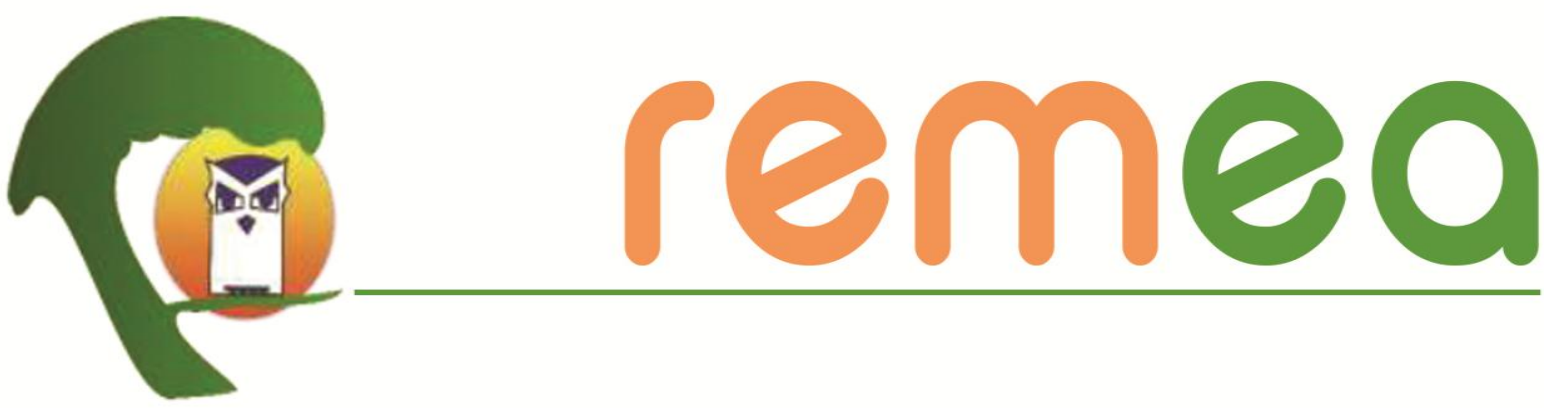

\title{
Apontamentos de pesquisas produzidas pelo NIPEEA como fluxos de reexistências de uma educação ambiental decolonial ${ }^{1}$
}

\author{
Martha Tristão ${ }^{2}$ \\ Universidade Federal do Espírito Santo - UFES \\ ORCID: https://orcid.org/0000-0002-8527-9332
}

Resumo: A educação ambiental decolonial será problematizada neste texto, a partir de algumas pesquisas desenvolvidas pelo Núcleo Interdisciplinar de Pesquisa e Estudo em Educação ambiental (NIPEEA), ${ }^{3}$ como uma máquina desejante, que pode engendrar linhas de fuga em meio ao poder axiomático do dispositivo da colonialidade. A educação ambiental decolonial promove fluxos decolonizadores que se articulam para além dos espaçostempos ${ }^{4}$ comunitários-escolares, pois se pode articular como máquina, uma máquina desejanteambiental ${ }^{5}$ que engendra fluxos de naturezasculturas. ${ }^{6}$ E são esses fluxos cartografados nas pesquisas, como movimentos de reexistências, que criam possibilidades e facilitam uma Educação ambiental decolonial.

Palavras-chave: Educação ambiental, Decolonial, Reexistências.

\footnotetext{
${ }^{1}$ Este artigo foi elaborado com as excelentes contribuições da Professora Helen Pessoa.

2 Professora titular do Programa de Pós-graduação em Educação (PPGE) da UFES, nos cursos de Mestrado e Doutorado. Coordena o Núcleo Interdisciplinar de Pesquisa e Estudo em Educação ambiental (NIPEEA) no Centro de Educação da UFES. E-mail: marthatristaoferreira@gmail.com

${ }^{3}$ O NIPEEA foi criado em 2005 e emergiu da necessidade de integração entre projetos que envolvem ensino, pesquisa e extensão, com vistas à consolidação de um grupo formado por professores e alunos dos cursos de graduação, mestrado e doutorado em Educação, do Programa de Pós-Graduação em Educação (PPGE/Ufes) e de egressos interessados.

${ }^{4}$ Como uma imbricação entre os conceitos, Alves (2001) desenvolve uma concepção com a qual também dialogamos neste texto, que compreende o espaçotempo escolar como dimensão material do currículo, composto de relações múltiplas entre múltiplos sujeitos, com saberes múltiplos, que aprendem/ensinam, o tempo todo, múltiplos conteúdos e de múltiplas maneiras.

${ }^{5}$ Compreendemos a Educação ambiental como uma máquina desejante, em suas articulações com as comunidades-escolas. Assim, como uma imbricação entre os conceitos, chamamos de máquina desejanteambiental, essa Educação ambiental que reexiste para além das escolas.

${ }^{6}$ Buscamos, através dessa imbricação conceitual, mostrar a indissociabilidade entre as naturezas e as culturas, que são múltiplas e plurais em suas formas de existir.
} 


\title{
Notas de investigación producidas por NIPEEA como flujos de reexistencia de una educación ambiental descolonial
}

Resumen: La educación ambiental decolonial será discutida en este texto, a partir de algunas investigaciones realizadas por el Centro Interdisciplinario de Investigación y Estudios en Educación Ambiental (NIPEEA), como una máquina deseante que puede engendrar líneas de vuelo en medio del poder axiomático del dispositivo colonial. La educación ambiental descolonial promueve flujos descolonizadores que se articulan más allá del espacio-tiempo comunidad-escuela, ya que puede articularse como una máquina, una máquina deseante ambiental que engendra flujos de naturalezas-culturas. Y estos flujos se mapean en la investigación como movimientos de reexistencia que crean posibilidades y facilitan la educación ambiental descolonial.

Palabras-clave: Educación ambiental, Decolonial, Reexistencias.

\section{Research notes produced by NIPEEA as flows of reexistence of a decolonial environmental education}

\begin{abstract}
Decolonial environmental education will be discussed in this text, based on some research carried out by the Interdisciplinary Center for Research and Study in Environmental Education (NIPEEA), as a desiring machine that can engender lines of flight in the midst of the axiomatic power of the device of coloniality. Decolonial environmental education promotes decolonizing flows that articulate beyond the community-school spacetimes, as it can articulate itself as a machine, an environmental desiring machine that engenders flows of natures-cultures. And these flows are mapped in research as movements of re-existence that create possibilities and facilitation of decolonial environmental education.
\end{abstract}

Keywords: Environmental education, Decolonial, Reexistences.

\section{Introdução}

Este é um momento de crise político-econômico-social muito delicado, não só em função dos dados noticiados (que torna o público meros espectadores), mas porque o acontecimento é o front de uma guerra. Todos os dias, dados estatísticos de corpos, de perdas e de danos são notificados. E é neste contexto que as pesquisas podem criar reexistências ${ }^{7}$ pois, por mais frágeis e precárias que possam parecer, os fluxos que vão sendo criados, os movimentos de pesquisa e práticas suscitam possíveis desejos de ruptura com uma sociedade, excessivamente, controlada por uma lógica imposta e que normaliza a morte precoce de mais de 600 mil pessoas no Brasil, vitimadas pela doença causada pelo

\footnotetext{
7 Fluxos que podem atuar como forças ativas na perspectiva nietzschiana (DELEUZE, 2007), criando a sustentabilidade das relações da vida. Compreendemos, em nossas pesquisas, que só a existência desses fluxos já são resistências ou, como desenvolvemos em conexão com os intercessores teórico-metodológicos e todas/os que compõem esses movimentos, as reexistências.
} 
novo coronavírus. ${ }^{8}$ É como argumenta Stengers (2015, p. 12): “a guerra econômica exige a presença de todos nós, essa guerra cujas vítimas não têm sequer o direito às honras, mas são intimadas a voltar por todos os meios à frente de batalha".

Em meio a todo esse sofrimento de perdas de vidas, de uma política antiecológica e negacionista, uma Comissão Parlamentar de Inquérito (CPI) é instaurada pelo Senado Federal Brasileiro, a fim de investigar ações e omissões do governo federal no enfrentamento da pandemia da Covid-19 - que adiou a vacinação no país (que poderia ter se iniciado em novembro de 2020, conforme revela a CPI) e nesse intervalo (novembro/2020 a julho/2021) mais que dobrou o número de mortes.

Os movimentos de reexistências e as pesquisas, que aqui defendemos, entrelaçam lutas e criam mundos possíveis, ${ }^{9}$ em meio a uma lógica econômica desenvolvimentista que busca formatar perfis, que possam ser facilmente sujeitados e docilizados pelas engrenagens da máquina da colonialidade. Porém, acreditamos que há fluxos decoloniais que atravessam essa estrutura e podem descodificar esses códigos coloniais; talvez, em uma dinâmica revolucionária do desejo, que não aceita situações de sujeição (DELEUZE; GUATTARI, 2011a).

Apostamos, assim, em uma educação ambiental decolonial, que pode promover fluxos decolonizadores, que se articulam para além dos espaçostempos comunitários e escolares, pois pode se articular como máquina, uma máquina desejanteambiental que engendra vida com toda sua potência e fluxos de naturezasculturas.

Deleuze e Guattari (2011a) desenvolvem os conceitos de máquinas molares e moleculares. Para os autores, em uma sociedade capitalista e/ou socialista, a estrutura social pode ser entendida como máquinas, tecem "diferenças" entre as máquinas molares e as moleculares, apesar do limiar tênue entre seus processos de produção. São molares as máquinas dominantes. Dentre elas, os autores exemplificam citando as máquinas sociais,

\footnotetext{
${ }^{8}$ O novo coronavírus é uma zoonose que pode ter surgido, segundo a Organização Mundial da Saúde (OMS), no final de 2019, no mercado de Wuhan (China), onde se comercializa animais silvestres vivos ou abatidos, sendo uma das maiores hipóteses de contágio do vírus para os humanos, causando severa síndrome respiratória aguda (SARS-CoV-2).

${ }^{9}$ Deleuze (1974) concebe um universo em que existem outros mundos possíveis em nosso mundo, outras histórias na história, em que proclamamos ingenuamente a nossa realidade: "Um possível que se obstina em passar por real" (p. 317).
} 
técnicas ou orgânicas; já as máquinas moleculares são as desejantes. Entretanto, longe de assumirem um caráter dicotômico nesses conceitos (esse ou aquele), os autores articulam que molares e moleculares coexistem (esse e aquele). Ou seja, apesar de as forças ativas, para Deleuze e Guattari, serem moleculares, coexistem ali as forças molares (reativas) prontas para cristalizar. Onde forças molares atuam, podem surgir fugas (PESSOA, 2020).

É esta educação ambiental decolonial que será problematizada neste texto, a partir de algumas pesquisas desenvolvidas pelo NIPEEA, como uma máquina desejante, que pode conceber linhas de fuga em meio ao poder axiomático do dispositivo da colonialidade. Segundo Tristão (2018), a educação ambiental vem produzindo uma narrativa em seu movimento educativo-ambiental de que é importante considerar em suas análises, as especificidades do lugar em suas relações com as comunidades. De acordo com a autora, a colonialidade pode nos ajudar na compreensão das formas de poder que ainda se impõe numa relação de controle indireto dos povos, do território e das naturezasculturas, ${ }^{10}$ sob a forma de usurpação dos saberes e das terras indígenas, dos seringueiros, dos povos atingidos pelas barragens nas Regiões Norte e Centro-Oeste do Brasil.

Neste contexto, uma Educação ambiental luta pela integração e articulação entre humanos e não humanos, pelas diferentes culturas locais com movimentos e fluxos reexistentes, valorizando a estreita relação simbiótica entre escolas e comunidades. Como uma máquina desejante que pode se articular, rizomaticamente, favorecendo desterritorializações do conhecimento reducionista e fragmentado para reterritorializar um conhecimento à vida.

Na primeira parte desse texto serão abordados os aportes teóricos e metodológicos norteadores das pesquisas desenvolvidas pelo NIPEEA. Em seguida, na tentativa de trazer algumas produções do grupo dos últimos anos, optamos por selecionar os trabalhos que foram apresentados durante as reuniões da Associação Nacional de Pesquisa e Pós-

\footnotetext{
${ }^{10}$ A escrita das duas palavras juntas é com a intenção de criar um sentido de dependência e co-relação, visto que as culturas são produzidas a partir das relações que os povos e comunidades estabelecem com as naturezas suscitando um universo diverso, um pluriverso como argumenta Latour (2004).
} 
Graduação em Educação (ANPEd) ${ }^{11}$ e buscamos localizá-los nas publicações do grupo de trabalho em educação ambiental (GT 22), ${ }^{12}$ que ocorreram entre o período de 2017 a 2019. Encontramos quatro trabalhos, que foram apresentados em três eventos: duas reuniões nacionais em 2017 e 2019; e uma reunião regional (Sudeste) em 2018.

\section{Movimentos de um campo de pesquisa em educação ambiental}

Na tentativa de acompanhar os movimentos que ensejam reexistências nas pesquisas em educação ambiental, é importante salientar o momento atual de crise mundial sanitária e política. ${ }^{13}$ Os movimentos que - primeiramente com demandas ambientais (antes de 1980), como preservação e conservação do meio ambiente, e depois considerando a dimensão socioambiental - ressaltam a importância de situar a Educação ambiental em uma discussão em nível global, com ações ambientalmente sustentáveis em níveis locais, visto que as consequências dos impactos socioambientais e da emergência climática atingem a humanidade, causando injustiças socioecológicas entre comunidades e populações mais vulneráveis. Os estudos de Acselrad (2002, p. 49) problematizam a questão da justiça ambiental, entrelaçando as lutas dos movimentos sociais nesse ensejo, "[...] recusando a reprodução da desigualdade de poder e denunciando as relações de dominação associadas à imposição desigual de danos ambientais".

Stengers (2015) contribui com esse debate, adensando mais essas questões, ao considerar a Terra como Gaia e inferir sobre a sua "intrusão" na emergência contemporânea:

\footnotetext{
${ }^{11}$ Entidade sem fins lucrativos que congrega programas de pós-graduação stricto sensu em Educação, professores e estudantes vinculados a estes programas e demais pesquisadores da área. A ANPEd tem por finalidade o desenvolvimento da ciência, da educação e da cultura, dentro dos princípios da participação democrática, da liberdade e da justiça social.

12 O GT 22 da ANPEd foi criado em 2004, consolidando a produção e demanda da pesquisa em Educação ambiental. Desde o início da década de 90, já havia estudos e pesquisas em Educação ambiental submetidos à aprovação nos vários GTs da ANPEd.

${ }_{13}$ Momento de contínuo desmonte das políticas ambientais e da Educação ambiental no Brasil, além de investigação na CPI da Pandemia (Senado Federal) de possíveis crimes de prevaricação e corrupção que envolve a negociação de vacinas, em meio a pandemia de COVID-19, pelo governo do presidente da extrema direita Jair Bolsonaro (a partir de 2019 até o momento da escrita deste texto).
} 
E Gaia, 'planeta vivo', deve ser reconhecida como um 'ser', e não assimilada a uma soma de processos, no mesmo sentido em que reconhecemos que um rato, por exemplo, é um ser: ela é dotada não apenas de uma história, mas também de um regime de atividades próprio, oriundo das múltiplas e emaranhadas maneiras pelas quais os processos que a constituem são articulados uns aos outros, a variação de um tendo múltiplas repercussões que afetam os outros (STENGERS, 2015, p. 38).

Gaia é suscetível, por isso deve ser nomeada como ser. Já não estamos lidando com uma natureza selvagem e ameaçadora, nem com uma natureza frágil, que deve ser protegida, nem com uma natureza que pode ser explorada à vontade (STENGERS, 2015, p. 39-40).

Assim, tentativas de respostas e novas maneiras de pensar e agir vêm sendo articuladas por movimentos socioambientais, no Brasil e em outros países, através de políticas de educação ambiental que são implementadas a partir das demandas desses movimentos - embora, atualmente, estejam sob forte pressão e marcadas por retrocessos, há tempos nunca imaginados ou vistos. Não cabe aqui questionarmos o mérito ou mesmo a efetividade dessas políticas em educação ambiental que estão sob ataque, mas sim problematizar que muitas delas, no caso da educação de modo mais amplo, ainda estão baseadas em uma lógica de mercado e na manutenção do capitalismo, mesmo que se remetam ao termo "desenvolvimento sustentável".

Defendemos que, ao invés da colonização de um determinado modelo de desenvolvimento e da adoção de uma única direção que continua insistindo com a mesma lógica, ao capitalizar os bens naturais, faz-se necessário pensar a partir de outras realidades e experiências locais e menores, tornando-as disponíveis e visíveis em uma realidade mais ampla, como uma forma de descolonização (TRISTÃO; VIEIRAS, 2017).

Alguns movimentos e pesquisas, hoje, tomam a dimensão social. Nessa perspectiva, a questão dos direitos humanos e dos direitos da natureza nas dinâmicas ambientais criam demandas mais amplas, antes reduzidas à conservação e à preservação de ecossistemas naturais, e incorporam em seus estudos a emergência climática, as desigualdades criadas, a degradação socioambiental e o racismo ambiental.

Sobre essa mudança de pensamento descolonizadora desses movimentos, Stengers (2015, p. 14-15) fornece pistas que ensejam esse "giro": 
Se estamos em suspenso, alguns já estão engajados em experimentações que buscam criar, a partir de agora, a possibilidade de um futuro que não seja bárbaro - aqueles e aquelas que optaram por deserdar, por fugir dessa 'guerra suja' econômica, mas que, 'fugindo, procuram uma arma', como dizia Gilles Deleuze. E, aqui, 'procurar' quer dizer, antes de tudo, criar, criar uma vida 'depois do crescimento econômico', uma vida que explora conexões com novas potências de agir, sentir, imaginar e pensar.

Apesar das codificações da máquina da colonialidade provocarem ressonâncias nas comunidades-escolas com a intenção de promover uma formação monocultural e tecnicista, observamos em nossas pesquisas que coexistem, nesses lugares, movimentos de reexistências que produzem composições curriculares que potencializam nomadismos, capazes de permitir o atravessamento da educação ambiental em uma perspectiva decolonial (PESSOA, 2020).

Para Deleuze e Guattari (1997, p. 53) o nomadismo não tem a ver com deslocamento físico, mas intensivo:

\begin{abstract}
E nesse sentido que o nômade não tem pontos, trajetos, nem terra, embora evidentemente ele os tenha. Se o nômade pode ser chamado de o Desterritorializado por excelência, é justamente porque a reterritorialização não se faz depois, como no migrante, nem em outra coisa, como no sedentário (com efeito, a relação do sedentário com a terra está mediatizada por outra coisa, regime de propriedade, aparelho de Estado...). Para o nômade, ao contrário, é a desterritorialização que constitui sua relação com a terra, por isso ele se reterritorializa na própria desterritorialização. É a terra que se desterritorializa ela mesma, de modo que o nômade aí encontra um território.
\end{abstract}

Assim, o nômade constitui ou busca constituir territórios com potência de transformação coletiva. Nesse sentido, precisamos potencializar esses fluxos nas escolascomunidades como movimentos possíveis de "descolonizar os currículos". É preciso almejar também uma mudança na relação entre a sociedade, o Estado e as indústrias/empresas que, atualmente, exercem uma influência direta no planejamento educacional e na estrutura organizacional das instituições de ensino. No caso específico de uma educação ambiental decolonial, não passa por simplesmente ter autonomia ou fazer frente às exigências de mercado, mas sim questionar e criar outras formas de existir diante da máquina capitalística que força uma intervenção irresponsável e inconsequente na natureza. 
Nessa perspectiva, nossas pesquisas tentam capturar os efeitos destas cristalizações nas instituições e nos movimentos, buscando compreender se ocorrem aberturas rizomáticas e reexistências às linhas duras e molares (DELEUZE E GUATTARI, 2011a). Observamos que os movimentos de reexistências podem favorecer essas aberturas na composição de currículos nômades - dinâmicos e abertos às problematizações que os contextualizam (PESSOA, 2020). Pensar o currículo nessa perspectiva auxilia a criar possibilidades frente aos desafios da educação ambiental.

Pessoa (2020), em sua pesquisa de doutorado, observa que esses movimentos de reexistências potencializam currículos nômades e facilitam o atravessamento da educação ambiental nas linhas, com tracejados molarmoleculares, que podem possibilitar nomadismos nas composições curriculares e transversalidade nos fronts das disciplinas e conhecimentos. Para a autora, assim como o nômade está sempre em desterritorialização, também é assim que funciona o currículo: sempre em movimento, rompendo com a estrutura tradicional imposta.

Apesar das tentativas, impositivas ou não, de reduzir a dimensão socioambiental ao "ambientalmente sustentável" com projetos e ações para "melhorar" ou "esverdear" as escolas e comunidades - o que poderia ser ressonância da máquina capitalística -, observamos, em nossas pesquisas, alguns tracejados de desejo que podem fluir nos movimentos, saberes, práticas e redes criados através das conexões tecidas entre o lugar e as culturas.

Stengers (2015, p. 122) compõe esse pensamento, ao dizer que "as conexões devem ser criadas, sempre precárias, jamais adquiridas de uma vez por todas". Nesse sentido, nossas pesquisas seguem esses tracejados, mesmo que possam parecer "precários" (pela redução das narrativas verdes do desenvolvimentismo), procurando observar e capturar a criação de conexões. E são esses fluxos que buscamos nas pesquisas, como movimentos de reexistências na criação de possibilidades e facilitação de uma educação ambiental decolonial, empenhada em explorar conexões que busquem recriar novas potências de pensar-viver-agir juntos. 
De acordo com Tristão (2016), a ênfase das pesquisas do NIPEEA tem correlacionado três dimensões: lugar, cultura e narrativa, reforçando o argumento de que a cultura residual, cotidiana, ordinária, dominante e emergente, está intrinsecamente associada à experiência vivida com o meio ambiente. Há algum tempo, nosso grupo vem se interessando em estabelecer uma relação entre o pensamento pós-colonial e a educação ambiental (TRISTÃO, 2018). Exploramos as formas de reexistências produzidas, as experiências de culturas com usos de práticas sustentáveis para garantir seus modos de vida e analisamos como comunidades-escolas desenvolvem formas de se relacionar com as naturezasculturas.

A noção de colonialidade é pertinente porque é contextualizadora e considera a importância histórica dos processos colonizadores no continente e o que esses processos suscitam: um novo universo de relações intersubjetivas, processos identitários culturais de dominação e de exploração entre e dentro de regiões. Além disso, discute o controle da natureza.

Os autores latinos, marcam um posicionamento político, de resistência ao introduzem um outro conceito, com uma corrente, da colonialidade, cunhada nos anos 2000, radicalizando o argumento pós-colonial no continente com a noção do "giro decolonial". Essa vertente traz uma profunda crítica ao eurocentrismo. A noção de colonialidade, criada nesse movimento, está associada aos mecanismos de controle que prevalescem com a modernidade, $o$ decolonial não pode ser confundido com descolonização, pois descolonização significa a superação do colonialismo, em termos históricos e temporais; a ideia de decolonialidade procura transcender a colonialidade, segundo Ballestrin (2013).

Nesse aspecto, interessa a esse grupo de pesquisa cartografar o que subverte a cultura como um ato de existir político, revolucionário de algumas comunidades-escolas, um desafio a regras e a normas impostas pelos processos colonizadores de uma cultura maior. Pois uma cultura menor fala e se expressa, narra seu coletivo e produz o novo em um devir cotidiano permanente. O que importa é aquilo que foge aos mecanismos de controle, o que escapa, criando fluxos de resistências (TRISTÃO, 2016). 
Portanto, os estudos realizados no núcleo de pesquisa, o NIPEEA/UFES, se situam numa busca permanente da correlação entre o lugar, as culturas e as produções narrativas dos sujeitos/comunidades/escolas. Na subseção a seguir, trazemos contribuições de algumas publicações de recentes trabalhos realizados pelo NIPEEA, como possibilidades de descolonização e de criação de processos de desconstrução das narrativas dominantes e de produção de novas subjetividades.

\section{Seguindo os fluxos das pesquisas publicadas pelo NIPPEA no GT 22 da ANPED}

Em 2017, na 38a Reunião Nacional da ANPEd, foi apresentado o trabalho "Resistências e relações de poder na produção cotidiana da Educação ambiental: uma problematização atravessada pelo crime socioambiental na Bacia do Rio Doce" (VIEIRAS, 2017). Neste trabalho, o autor compartilha parte de sua pesquisa de doutorado, que desenvolve problematizações em torno de enfrentamentos e tensões que contextualiza a escola-comunidade e os crimes ambientais na região.

Vieiras (2017), dialogando com Foucault, cartografa os movimentos entre estudantes do campus de Colatina do Instituto Federal do Espírito Santo (IFES), a partir dos efeitos que ressoam do crime socioambiental na Bacia do Rio Doce, causado pelo rompimento de uma barragem de rejeitos provenientes da extração de minério de ferro no Município de Mariana/MG. ${ }^{14}$ No texto, o autor busca aproximar o conceito do "cuidado de si" e/ou "modos de existência" de uma perspectiva da Educação ambiental e suas implicações para a produção de outros mundos possíveis. Para isso, lança mão de observações empíricas, conversas e/ou entrevistas produzidas num determinado espaço-tempo em que se deu o crime socioambiental, problematizando a influência da lógica desenvolvimentista/capitalista nos mais diferentes espaços, inclusive na produção de subjetividades. Nesse contexto, o autor aposta na produção de subjetividades agenciada por princípios da Educação ambiental com potencial para criar outras relações com o espaço.

\footnotetext{
14 Rompimento de uma barragem de rejeitos de mineração denominada "Fundão", controlada pela Samarco Mineração S.A., um empreendimento conjunto das maiores empresas de mineração do mundo, a brasileira Vale S.A. e a anglo-australiana BHP Billiton.
} 
Nesta mesma reunião nacional (38a ), encontramos o trabalho "Contextosproduções em coletivos da docência: sentidos congruentes com os territórios do meio ambiente local" (ALMEIDA, 2017), em que a autora tece uma Educação ambiental a partir das narrativas produzidas por docentes em encontros coletivos. Em diálogo com Maturana e Varela; Deleuze e Parnet; e Larrosa, a pesquisadora observa movimentos que potencializam a existência e pertencimento da docência acoplada ao ambiente de convivência. Ao acompanhar os movimentos da pesquisa, ela problematiza e reflete sobre a docência e o saber docente-ambiental que, neste texto, relacionamos aos engendramentos da máquina desejanteambiental ao promover fluxos de resistências na formação, ressaltando o desejo de territorializar as relações de pertencimento à rede socioambiental.

Nesta mesma perspectiva, observamos também a pesquisa "Cartografia da ideia de cultura: narrativas e resistências de uma comunidade" (REZENDE, 2017). Na pesquisa, a autora problematiza a ideia da cultura presente nas narrativas de professores e personagens que compõem uma comunidade tradicional do município de Vitória/ES. ${ }^{15}$ Em diálogo com Guattari e Rolnik, a autora busca compreender os sentidos de cultura, na tentativa de captar o discurso maquínico capitalístico, bem como os movimentos de desterritorialização e resistência.

Nesta pesquisa cartográfica, Rezende (2017) acompanha os movimentos de resistência por meio da escuta atenta e produção de narrativas com os membros da comunidade e dos professores de diferentes escolas que atuam no território investigado. No caminho, observa que os saberesfazeres implicados nas narrativas desses personagens podem revelar intenções, fluxos, desejos, sonhos e resistência da comunidade tradicional, ressaltando a cultura como um campo de poder e possibilidades.

Também acompanhamos esses fluxos na 13a Reunião Científica Regional da ANPEdSudeste em 2018, em que foi apresentado o trabalho "Educação ambiental e movimentos de

\footnotetext{
${ }^{15}$ Comunidade localizada no bairro de Goiabeiras, conhecida como Paneleiras de Goiabeiras, por conta da produção de panelas de barro. O ofício de fazer panelas é uma tradição e, desde 2002, faz parte do Patrimônio Cultural Brasileiro, considerado como um Bem Cultural de Natureza Imaterial. Esse processo manual de fabricação artesanal de cerâmica tem origem indígena e se mantém há várias gerações (REZENDE, 2017).
} 
re-existências na universidade: primeiras aproximações com o campo problemático" (PESSOA, 2018). Neste trabalho, a autora também dialoga com sua pesquisa de doutorado, produzindo uma cartografia dos movimentos criados pelo coletivo de agroecologia Kapi'xawa e seus efeitos pelo campus universitário e as comunidades rurais e locais de Alegre/ES. Nas primeiras pistas produzidas pela pesquisa, a autora é afetada pelas relações afetivas que se desenvolvem com os estudantes, os produtores rurais e demais membros das comunidades, que criam possibilidades para fluir uma educação ambiental decolonial.

No decorrer da pesquisa de doutorado, outro trabalho é apresentado, na 39a Reunião Nacional da ANPEd em 2019, com o título "A potência dos coletivos estudantis na universidade e as possibilidades para a educação ambiental" (PESSOA, 2019), no qual a cartografia realizada encontra, além do coletivo Kapi'xawa, o movimento Kizomba. Nas conexões criadas pelos coletivos nas comunidades academicolocalrurais, a autora observa a produção de educações ambientais decoloniais e nômades que se entremeiam aos currículos inventados/criados.

Assim, os estudos apresentados vão tecendo as problemáticas decoloniais, na busca por produzir reexistências, valendo posicionar-se contra o que se normaliza pelos meios midiáticos - o genocídio e a mercantilização do meio ambiente. $E$, vale ressaltar que, ler esses trabalhos nos fazem lembrar por que lutamos.

\section{A potência da pesquisa narrativa e cartográfica em conexão com os movimentos de reexistências}

A opção aqui é discorrer sobre o início e o caminho dos estudos desenvolvidos por Pessoa (2019), ${ }^{16}$ em sua pesquisa de doutorado, apresentada durante a 39a Reunião Nacional da ANPEd, última reunião antes da pandemia.

Pessoa (2019) fundamenta a pesquisa com os aportes teórico-metodológicos de Deleuze e Guattari (2011b), buscando produzir uma cartografia dos movimentos de

\footnotetext{
${ }^{16}$ A tese de doutorado de Pessoa (2020) adquire uma importância nesse artigo pela sua articulação conceitual, teórica e metodológica com a pesquisa aprovada no CNPq "Decolonizar o pensamento: apontamentos e entrelaçamentos epistêmicos e metodológicos com a Educação ambiental", que abarcou os estudos desenvolvidos pelo NIPPEEA neste período de 2018-2021.
} 
reexistências no campus sul da universidade Federal do Espírito Santo (UFES), acompanhando os fluxos nas redes de conversações (MATURANA, 2001) e a produção de narrativas (TRISTÃO, 2013).

A pesquisa cartográfica se inicia em 2017, com os primeiros contatos com o coletivo Kapixa'wa, com a participação em algumas assembleias e encontros de organização coletiva. Em 2018, continua a manter contato com o coletivo e, em 2019, ao acompanhar os encontros-conversa, encontros-formação e encontros-evento ${ }^{17}$ pelo campus, depara-se com outro coletivo, o Movimento Kizomba. ${ }^{18}$ A pesquisa segue os fluxos de reexistências nas redes de conversações no campus, por meio de gravações, filmagens e registros fotográficos.

Nos primeiros encontros, foram realizadas provocações sobre as produções de culturas locais, as atuais políticas econômicas, a devastação socioambiental e os impactos nas formações. Em um segundo movimento, foi realizada uma cartografia entre redes de conversações nos encontros-conversa-formação-evento e na participação em diversas atividades, com o objetivo de perceber a possível criação de movimentos de reexistências, ao seguir os fluxos desejantes, e observando se potencializavam, ou não, os engendramentos da máquina desejanteambiental.

No início, observa-se alguns tracejados molarmoleculares nas enunciações coletivas que auxiliam na produção de pistas, como quando abordam a dificuldade em assimilar o "sustentável” como algo pronto/dado: “[...] a pessoa fala: 'Ah, é sustentável'. Mas, às vezes, a pessoa nem sabe o que é sustentável. Fica muito geral" (ENCONTRO-CONVERSA 1).

De fato, essa é uma questão complexa, que também acreditamos não possa ser reduzida a algumas ações "sustentáveis" ou "verdes". Guimarães e Sampaio $(2012,2014)$ nos auxiliam a fomentar essa problematização ao desenvolverem estudos sobre a captura da

\footnotetext{
${ }^{17}$ Acontecimentos organizados pelos movimentos encontrados na cartografia.

18 O campus sul da UFES compreende os municípios de Alegre (sede), Jerônimo Monteiro e São José do Calçado, localizados na região do Caparaó Capixaba/ES. Nessa pesquisa, os movimentos de reexistências foram acompanhados na sede do campus, em Alegre, onde se concentram as atividades acadêmicas. De acordo com Pessoa (2020), os coletivos encontrados, Kapi'xawa e Movimento Kizomba, surgem através de demandas estudantis, como espaços de livre aprendizado e discussão.
} 
sustentabilidade como um clichê - dispositivo da sustentabilidade. Nesse contexto, as enunciações vão sugerindo as interligações, conexões que podem ocorrer até chegar à relação dos estudantes nessa teia, incluindo a questão da ética.

Segundo Pessoa (2020), nesse movimento de possível fuga ao clichê, começam a surgir algumas iniciativas, talvez tracejadas de desejo coletivo e/ou efeitos de arborescência (na redução da educação ambiental), auxiliando na produção de mais pistas:

- Aqui tem vários exemplos legais, como: descarte de materiais escolares, caneta, pincéis. Tem ali, no prédio, um lugar de descarte. Só que não tem uma divulgação. Está num lugar que não é tão acessível também, era para estar em um lugar com muito mais acesso dos alunos. Então eu acho que parte de iniciativas assim. Tipo assim, ter a iniciativa, mas o projeto não é tão explanado, muitas pessoas não conhecem.

- A gente estava falando dos pontos ruins, mas agora estamos falando dos pontos positivos. Há pouco tempo não tinha esse jardim. Esse jardim foi criado há o quê? Uns quatro meses? Então eu creio que esse jardim foi uma iniciativa sustentável.

- Foi uma iniciativa sustentável porque utilizou a mão de obra dos alunos, material que tinha no campus já.

- Melhora tanto o aspecto da universidade como até o humor das pessoas. Por verem uma coisa mais bonita, elas acabam, sei lá, ficando mais agradáveis também (ENCONTRO-CONVERSA 1).

Essa questão levantada na rede de conversação sobre a criação do jardim como uma prática da educação ambiental em conexão com a comunidade acadêmica: "Melhora tanto o aspecto da universidade como até o humor das pessoas. Por verem uma coisa mais bonita, elas acabam, sei lá, ficando mais agradáveis também" (ENCONTRO-CONVERSA 1) pode ser relacionada com a questão do encantamento que Tristão (2013, p. 854) desenvolve: "Como já temos argumentado sobre o encantamento provocado pela educação ambiental, pela sua conectividade com uma razão sensível em que a natureza é encarnada na produção de subjetividades [...]". Pensamos que essa produção de subjetividades também pode ressoar nas composições curriculares.

Nesses múltiplos agenciamentos, que também se moviam/movem a outros, emerge a possiblidade de currículos nômades, que não se fechavam ao conteúdo das propostas curriculares dos cursos de graduação. Se faltavam/faltam ideias para a instituição permitir o 
atravessamento da educação ambiental na formação acadêmica, sobravam/sobram possibilidades para os agentes coletivos ${ }^{19}$ em suas redes de conversações: "No fortalecimento das campanhas e dos grupos que já existem [...]. E movimentar essas ações para transformar mesmo, talvez não esse espaço, mas que a UFES dê um espaço para a gente trabalhar mesmo" (ENCONTRO-CONVERSA 5).

Em diálogo com Guattari (1987), a autora problematiza se os movimentos pesquisados reexistem em meio aos fluxos colonizadores para além do campus, onde agenciamentos coletivos de enunciação de luta podem auxiliar na produção de prováveis pistas: “A gente está aí para uma nova cultura política, tirar essas coisas velhas que estão aí carcomidas na nossa cultura, e incluir, né? Não excluir as pessoas" (ENCONTRO-CONVERSA $5)$.

Assim, pensamos que o desejo pode ser decolonizador, pois, como ressaltam Deleuze e Guattari (2011a, p. 158), “[...] não aceita nenhuma situação de exploração”. Nesta mesma linha, agem os prováveis fluxos cartografados, que em movimentos rizomáticos, podem se articular, reexistindo nas instituições, atravessando uma Educação ambiental que se aproxima de uma perspectiva decolonial.

Ao acompanhar as redes de conversações movidas pelos agentes coletivos, algumas ações e acontecimentos foram fornecendo pistas que problematizam a possibilidade dos coletivos na composição dos movimentos de reexistências. Como quando investiga se os agentes coletivos gostariam de liderar o grupo e todos se manifestaram contrários ao modelo hierarquizado, mostrando o princípio da multiplicidade, que talvez possamos observar na enunciação: "É um movimento horizontal em que não existe assim 'Ah, eu sou maior que você, eu vou fazer isso, então você é menor, então me obedece'. Não existe isso" (ENCONTRO-CONVERSA 5).

\footnotetext{
${ }^{19}$ De acordo com Pessoa (2020), a partir do momento em que os indivíduos integram com o coletivo, passam a produzir subjetividades que se articulam como agentes singulares em agenciamentos coletivos. Apesar da pesquisa ter se iniciado com estudantes do campus, ela observa que os movimentos também eram compostos por outras/os agentes, como servidores atuantes na universidade e demais membros das comunidades local e rural.
} 
Com relação ao envolvimento e ao apoio financeiro, a pesquisa destaca que a maioria dos estudantes faz parte dos coletivos voluntariamente e, em alguns casos, contribui com uma mensalidade pequena para eventuais custos do grupo. Quando há a necessidade de valores referentes à participação em eventos ou reuniões com outros coletivos, os participantes recorrem, geralmente, a rifas ou bazares (com peças doadas pela comunidade acadêmica): “Cada um colabora da forma que pode” (ENCONTRO-CONVERSA 10).

Os repasses de ações movidas pelos agentes coletivos ou em articulação com outros movimentos sociais são realizados em reuniões semanais - no caso do Kapi'xawa, as reuniões e assembleias acontecem em uma sala, atrás da quadra de esportes (espaço cedido pela universidade); já o Kizomba promove encontros em variados espaços. A autora associa que as articulações dos agentes coletivos para criar possibilidades, em meio aos poucos recursos, talvez suscitam o princípio da ruptura assignificante, que atravessa as barreiras impostas pela estrutura e cria linhas de desterritorialização/reterritorialização.

$\mathrm{Na}$ cartografia, essa pesquisa encontra outras pistas que mostram indícios dos princípios da conexão e da heterogeneidade, ao verificar que os coletivos possuem agendas de atividades que são organizadas coletivamente. Além de rodas de conversa com as comunidades, oficinas de capoeira com crianças e jovens em vulnerabilidade social, toda semana, o Kapi'xawa organiza mutirões para ajudar comunidades rurais locais e uma feira agroecológica na universidade. Ademais, também promove encontros-formação e encontros-eventos entre eles e outros movimentos - estudantis, comunitários, sociais.

As relações que o coletivo estabelece com a comunidade rural é familiar. Há trocas de trabalho e experiências nas propriedades por produtos que são colhidos posteriormente. Isso ocorre desde a fundação do grupo, há 33 anos. Durante as redes de conversações, observamos que, apesar de suas obrigações acadêmicas, os agentes coletivos fazem questão de participar desse mutirão, que geralmente acontece durante os finais de semana. Na enunciação coletiva, podemos constatar as ressonâncias dessas ações em imbricação com a Educação ambiental: 'A gente está aqui fortalecendo os agricultores que não usam isso [referindo-se aos agrotóxicos], sabe? Isso é ser sustentável também. É você estar na luta e ajudando a galera' (ENCONTRO-CONVERSA 3) (PESSOA, 2020, p. 142). 
Nesse sentido, as composições curriculares podem ser tecidas coletivamente: na organização de encontros-formação, com temas diversos, como feminismo negro, autogestão, políticas sociais, permacultura, entre outros temas; na produção de oficinas, como as de capoeira; nas enunciações coletivas, durante as redes de conversações; na criação de encontros-eventos para a comunidade; na produção de textos; e nos cantos, sorrisos e trocas de afeto.

Além disso, a pesquisa acompanha alguns agentes coletivos que continuam a compor os movimentos, mesmo após a conclusão de seus cursos de graduação. A composição, geralmente, ocorre quando os agentes coletivos procuram outras abordagens curriculares, nas quais se sintam "parte de".

O que ocorre, na narrativa de insatisfação com as propostas curriculares acadêmicas. Todos anseiam por uma "outra" proposta curricular, que seja aberta e flexível, que possa ser incluída (visibilizada) - o que é compreendido como uma composição curricular nômade:

[...] a gente veio para o Kapi'xawa porque a gente não tinha nada disso [no curso]. Eu tenho certeza de que a gente, dentro do curso, não aprende nada sobre Panc [plantas alimentícias não convencionais] e a gente aprende com a Dona Inês [agricultora rural] na feira. Então, tem coisa muito importante que a gente não aprende lá (ENCONTRO-CONVERSA 3, grifos nossos).

Assim, eu realmente me apaixonei pela Kizomba, quando eu vi a luta desse movimento dentro da universidade, a dificuldade de trazer para dentro da universidade a cultura, em que todos nós possamos falar, ouvir e sem repressão, sem nada do tipo [...] (ENCONTRO-CONVERSA 5, grifos nossos).

Nessa cartografia, as pistas encontradas demonstram que os coletivos podem compor com os movimentos de reexistências na universidade e para além dela. Apesar de ressaltar a potência dos coletivos na composição destes movimentos em sua pesquisa, ao explorar conexões e criar novas possibilidades de pensar e agir, Pessoa (2020) compreende que esse movimento pode ser maior, incluindo vários outros agentes coletivos que, talvez, a sua pesquisa de doutorado não aborde. O que acreditamos ser compreensível, em virtude de tantas outras pesquisas as quais essa se complementa. 
Ao atribuirmos aos movimentos de reexistências os princípios do rizoma de Deleuze e Guattari (2011b), entendemos as conexões múltiplas que podem ocorrer, mesmo em panoramas de crise como no atual cenário de colapso ambiental-político-econômico-social. No acompanhar das redes sociais dos movimentos aqui trazidos (KAPIXAWA, 2021; KIZOMBA, 2021), podemos verificar que os fluxos continuam e seguem se articulando em meio às engrenagens da máquina da colonialidade, que se atualiza constantemente. Mas isso não impede os fluxos desterritorializados pela máquina desejanteambiental.

\section{Considerações finais}

Importante considerar alguns potenciais desafios da Educação ambiental, entendida, de modo geral, como uma prática potencializadora da vida, portanto, de reexistência. Tristão (2012) menciona em um trabalho anterior - realizado em 2001, com reedição em 2012 -, quatro grandes desafios: enfrentar a multiplicidade de visões, superar a visão reducionista, superar a pedagogia das certezas e problematizar a lógica da exclusão. Atualmente, incluímos como um componente de seu repertório e de sua epistemologia fronteiriça, a descolonização do pensamento como alerta diário para a pesquisa. Seria a Educação ambiental decolonial, em suas articulações transgressoras, capaz de inventar caminhos de fuga em meio aos mecanismos de controle?

Para tanto, a aposta que fazemos é no atravessamento de uma educação ambiental decolonial, múltipla e revolucionária que, imbricada às micropolíticas dos movimentos de reexistências, pode atravessar currículos nômades. Aquela que se articula com os movimentos sociais e com a cultura local, tece fluxos de produção curricular e que reexiste, mesmo que tentem estrangulá-la em disciplinas e em ações pontuais e esporádicas. A maioria de suas ressonâncias são informais e transgressoras. Nem mesmo a sua ausência nos currículos é capaz de impedir os fluxos descolonizados pela máquina desejanteambiental.

Uma máquina desejanteambiental que pode, talvez, ser potencializada pelos movimentos de reexistências como os que as pesquisas, aqui apresentadas, mapeiam. Movimentos que podem se articular como máquinas de luta (NEGRI; GUATTARI, 2017) em 
meio a um contexto de desmonte e tentativas de controle pela máquina capitalística da colonialidade, lutando por novos espaços de liberdade. Movimentos que compõem currículos nômades com as comunidades, criando potências de agir, sentir, imaginar e pensar juntos, que buscam recriar relações socioafetivas que foram descodificadas ao longo dos tempos.

\section{Referências}

ACSELRAD, Henri. Justiça ambiental e construção social do risco. Desenvolvimento e Meio Ambiente, Editora UFPR, n. 5, p. 49-60, jan./jun. 2002.

ALMEIDA, Denize Mezadri. Contextosproduções em coletivos da docência: sentidos congruentes com os territórios do meio ambiente local. Trabalho apresentado no GT 22. 38a Reunião Nacional da Associação Nacional de Pós-Graduação e Pesquisa em Educação, realizada de 10 a 5 de outubro de 2017, na Universidade Federal do Maranhão, campus Dom Delgado, São Luís/MA, 2017.

ALVES, Nilda. Imagens das escolas: sobre redes de conhecimentos e currículos escolares. Educ. Rev. [on-line], n.17, p. 53-62, 2001.

BALLESTRIN, Luciana. América Latina e o giro decolonial. Revista Brasileira de Ciência Política, Brasilia, n.11,p. 89-117, maio/ago. 2013.

COVID, Brasil. Painel de casos de doença pelo coronavírus 2019 (COVID-19) no Brasil pelo Ministério da Saúde. Disponível em: https://covid.saude.gov.br/. Acesso em: 14 jul. 2021.

DELEUZE, Gilles. Lógica do sentido. Tradução de Luiz Roberto Salinas Fortes. São Paulo: Perspectiva, Ed. da Universidade de São Paulo, 1974.

DELEUZE, Gilles. Nietzsche. Tradução de Alberto Campos. Lisboa: Edições 70, 2007.

DELEUZE, Gilles; GUATTARI, Félix. Mil Platôs: Capitalismo e Esquizofrenia, v. 5. Tradução de Peter Pál Pelbart e Janice Caiafa. São Paulo: Editora 34, 1997.

DELEUZE, Gilles; GUATTARI, Félix. $\mathbf{O}$ anti-édipo: capitalismo e esquizofrenia. Tradução de Luiz B. L. Orlandi. 2. ed. São Paulo: Editora 34, 2011 a.

DELEUZE, Gilles; GUATTARI, Félix. Mil platôs: capitalismo e esquizofrenia., v. 1, 2. ed. São Paulo: Editora 34, 2011b. 
GUATTARI, Félix. Revolução molecular: pulsações políticas do desejo. Tradução de Suely Belinda Rolnik. 3. ed. São Paulo: Editora Brasiliense, 1987.

GUIMARÃES, Leandro Belinaso; SAMPAIO, Shaula Maíra Vicentini de. O dispositivo da sustentabilidade: pedagogias no contemporâneo. Perspectiva, Florianópolis, v. 30, n. 2, p. 395-409, maio/ago. 2012.

GUIMARÃES, Leandro Belinaso; SAMPAIO, Shaula Maíra Vicentini de. Educação ambiental nas pedagogias do presente. Em Aberto, Brasília, v. 27, n. 91, p. 123-134, jan./jun. 2014.

KAPI'XAWA, Grupo de Agricultura Ecológica. Instagram: kapixawa_agroecologia. Disponível em: https://www.instagram.com/kapixawa_agroecologia/. Acesso em: 14 jul. 2021.

KIZOMBA, Movimento. Instagram: kizomba_br. Disponível em: https://www.instagram.com/kizomba_br/. Acesso em: 14 jul. 2021.

LATOUR, Bruno. Políticas da natureza: como fazer ciência na democracia. Bauru: Edusc, 2004.

MATURANA, Humberto. Cognição, ciência e vida cotidiana. Organização e tradução de Cristina Magro e Victor Paredes. Belo Horizonte: Ed. UFMG (Humanitas), 2001.

MBEMBE, Achille. Necropolítica: biopoder soberania estado de exceção política da morte. Arte \& Ensaios (revista do Ppgav/EBA/Ufrj), n. 32, dez. 2016.

NEGRI, Antônio; GUATTARI, Felix. As verdades nômades: por novos espaços de liberdade. Tradução de Mario Antunes Marino e Jefferson Viel. São Paulo: Autonomia Literária e Editora Politeia, 2017.

PESSOA, Helen Moura. Educação ambiental e movimentos de re-existências na universidade: primeiras aproximações com o campo problemático. Trabalho apresentado no GT 22. 13a Reunião Regional Sudeste da Associação Nacional de Pós-Graduação e Pesquisa em educação, realizada de 15 a 18 de julho de 2018, na Universidade Estadual de Campinas, Campinas/SP, 2018.

PESSOA, Helen Moura. A potência dos coletivos estudantis na universidade e as possibilidades para a educação ambiental. Trabalho apresentado no GT 22. 39a Reunião Nacional da Associação Nacional de Pós-Graduação e Pesquisa em Educação, realizada de 20 a 24 de outubro de 2019, na Universidade Federal Fluminense, Niterói/RJ, 2019. 
PESSOA, Helen Moura. Cartografia dos movimentos de reexistências na universidade: possibilidades de agenciamentos da máquina desejanteambiental. 2020. Tese (Doutorado em Educação) - Universidade Federal do Espírito Santo, Vitória, 2020.

REZENDE, Fernanda Freitas. Cartografia da ideia de cultura: narrativas e resistências de uma comunidade. Trabalho apresentado no GT 22. 38a Reunião Nacional da Associação Nacional de Pós-Graduação e Pesquisa em Educação, realizada de 10 a 5 de outubro de 2017, na Universidade Federal do Maranhão, campus Dom Delgado, São Luís/MA, 2017.

STENGERS, Isabelle. No tempo das catástrofes: resistir à barbárie que se aproxima. Tradução de Eloisa Araújo Ribeiro. São Paulo: Cosac Naify, 2015.

TRISTÃO, Martha. A educação ambiental e a emergência de uma cultura sustentável no cenário da globalização. R. Inter. Interdisc. INTERthesis, Florianópolis, v. 9, n.1, p. 207-222, jan./jul. 2012.

TRISTÃO, Martha. Uma abordagem filosófica da pesquisa em educação ambiental. Revista Brasileira de Educação, v. 18, n. 55, p. 847-860, out./dez. 2013.

TRISTÃO, Martha. Educação ambiental e a descolonização do pensamento. Rev. Eletrônica Mestr. Educ. Ambient., Edição especial, p. 28-49, jul. 2016.

TRISTÃO, Martha (Org.). A educação ambiental e o pensamento pós-colonial: narrativas de pesquisas. Curitiba: CRV, 2018.

TRISTÃO, Martha; VIEIRAS, Rosinei Ronconi. Decolonizar o pensamento: apontamentos e entrelaçamentos epistêmicos com a educação ambiental. Rev. Eletrônica Mestr. Educ. Ambient., Edição especial, XVI Encontro Paranaense de educação ambiental, p. 103-117, set. 2017.

VIEIRAS, Rosinei Ronconi. Resistências e relações de poder na produção cotidiana da educação ambiental: uma problematização atravessada pelo crime socioambiental na Bacia do Rio Doce. Trabalho apresentado no GT 22. 38a Reunião Nacional da Associação Nacional de Pós-Graduação e Pesquisa em Educação, realizada de 10 a 5 de outubro de 2017, na Universidade Federal do Maranhão, campus Dom Delgado, São Luís/MA, 2017. 